\title{
THE IMPACT OF SUPPLY CHAIN LEADERSHIP AND FOLLOWERSHIP ON CSR: AN EMPIRICAL STUDY ABOUT A PORTUGUESE ENERGY SUPPLIER
}

\author{
Pedro Fontoura', Arnaldo Coelho ${ }^{2}$
}

\begin{abstract}
1 University of Coimbra, Faculty of Economics, Portugal, ORCID: 0000-0001-7218-6770, ptg.fontoura@gmail.com; 2 University of Coimbra, Faculty of Economics, Portugal, coelho1963@hotmail.com.
\end{abstract}

\begin{abstract}
Purpose: The aim of this investigation is to identify the impact of the supply chain leadership (SCL) and followership (SCF) on corporate social responsibility (CSR), considering the moderator role of the supply chain leadership dependency (SCLD). Additionally, we considered the mediating effects of information sharing (IS), shared values (SV) and purchasing social responsibility (PSR), since these variables may help understand the chain of effects that leads to a sustainable supply chain.

Methodology: This study uses a structured questionnaire to gather data from a cross-sectional sample of 425 supply chain partners from the biggest Portuguese's energy supplier. Structural Equation Modelling is used to test the proposed hypotheses, and a multi-group analysis is conducted to find how suppliers' dependency can impact on the suggested relationships.

Findings: SCL has a positive impact on IS, SV and PSR while SCF has a positive impact on IS and SV. IS, PSR and SV have a positive impact on CSR. SCF has a direct impact on CSR, while SCL only shows indirect effects throughout the effects of the mediating variables. Dependency appears to moderate some of the proposed relationships.

Implications/Originality: Better understanding the impacts and the chain of effects between supply chain leadership and CSR, also considering the role of dependency as moderating variable. The overall results may support the importance of a truly sustainable business leadership capable to promote social responsibly along the entire supply chain. It is a new approach of supply chain management, identifying how a social responsible company may lead their suppliers to adopt and develop a true and committed social responsible behaviour, and contribute to a better world.

Limitations: The research considers only one company suppliers. The relationships between variables need to be explored in other practical case studies and longitudinal investigations to improve the possibility of generalisations.
\end{abstract}

Keywords: Supply chain leadership, supply chain followership, purchasing social responsibility, corporate social responsibility, sustainable supply chain management.

JEL Classification: M14, L14, L25, L97.

APA Style Citation: Fontoura, P., \& Coelho, A. (2020). The Impact of Supply Chain Leadership and Followership on CSR: An Empirical Study about a Portuguese Energy Supplier. E\&M Economics and Management, 23(1), 75-92. https://doi.org/10.15240/tul/001/2020-1-006

\section{Introduction}

Sustainability is a theme that has gained interest among researchers and practitioners due to the increase of stakeholder awareness regarding environmental and social issues. In this context, the purchasing power of a company may turn out to be an important booster to bring positive changes to society. Corporations have to use this power to accomplish a goal and turn their supply chain in a driver for inclusive growth 
(Szegedi \& Kerekes, 2012). Consequently, businesses have become conscious of the requirement of developing strategies, which can spread their usual corporate governance methods beyond the company's borderline to their supply chain partners. According to Keating, Quazi and Kriz (2007), the appearance of purchasing approaches in favour of Corporate Social Responsibility (CSR) is the most noticeable display of this extension.

According to previous works, the literature established that a positive effect of company's leadership in CSR enables sustainable supply chain management (SSCM) resulting in benefits for all supply chain partners. Although leadership is frequently point out as crucial in every management initiatives, it is important not to forget the other side of leadership, namely the followership. These two structures can be considered reciprocal. Still, in the complex supply chain context, it is essential to deepen some aspects related to leadership-followership dichotomy, where literature do not provide enough comprehension, namely how to use a leadership position to improve social responsibility behaviour of the suppliers and deepen the understanding of followers' behaviour regarding supply chain leaders influence, since other variables can contribute to the expected outcomes, namely the supply chain leadership dependency (Cadden, Marshall, \& Humphrey, 2015). To fill this gap, our goals are to link the supply chain leadership (SCL), the supply chain followership (SCF) and corporate social responsibility (CSR), mediated by the roles of information sharing (IS), shared values (SV) and purchasing social responsibility (PSR), since these variables contribute to a better understanding of leadership and followership phenomena as key drivers of SSCM. With this belief, we hope to better understand the impacts and the chain of effects between supply chain leadership and CSR, also considering the role of dependency as moderating variable. The overall results may support the importance of a truly sustainable supply chain leadership, capable to promote social responsibly along the entire supply chain, therefore contributing to a better world.

\section{Research Background and Hypotheses Development} 1.1 CSR and Supply Chain

The concept of corporate social responsibility (CSR) is not consensually accepted, because there are different definitions, tendencies, points of view and models to explain its ground. Carroll's well-known definition of CSR is "The social responsibility of business encompasses the economic, legal, ethical and discretionary expectations that a society has of organizations at a given point in time" (Carroll, 1979, p. 500). Lantos (2001) states that CSR can be seen in the influence that business strategies and actions have in the community, socially and environmentally speaking. CSR exists when corporations look beyond the economic incomes and are connect with moral values, transparency and respect for the communities in which they operate. However, the way in which a corporation thinks has suffered deeps changes since Friedman (1962) stated that a company had the single concern of maximising their owners' and shareholders' prosperity. Considering this scenario, the most often used and discussed CSR dimensions are: taking stakeholders' points of view, social, economic and environmental dimensions, and voluntary application.

A main test for businesses is understanding the influence that CSR has on internal and external stakeholders. Therefore, the corporations that want the improvement of how sustainable their supply chains are, have to take the initiative in managing their suppliers through a series of business activities (Keating, Quazi, \& Kriz, 2007). Walker et al. (2008) considered that through sustainable supply chain management, companies might strengthen their risk management and minimize possible risks in their external collaborations and subcontractors. Tang and Zhou (2012) suggest the correlation between profitability and sustainability. Rajeev et al. (2017) considers that international community is stressing the adoption of sustainable production and consumption practices. These author conducted a literature review to understand the evolution of the body of knowledge on SSCM, showing that (i) studies in developed economies were far matured than, (ii) there was a significant surge in the quantity of studies after 2011, which may be attributed to the growing concern of researchers and practitioners to social and environmental dimensions. Businesses have long considered their economic prospects, but a clear lack of sensitivity to social issues is apparent.

Responsible Supply Chain Management appeared in the 1990s as a corporate reaction 
to human rights violations (e.g. child labour, discrimination and safety and health neglect) that appeared in the supply chain. According Szegedi and Kerekes (2012) businesses can have the opportunity of influence in a constructive way their suppliers' social and environmental performance, as a result of their purchasing activities. The association between the purchasing function and CSR was defined as Purchasing Social Responsibility (PSR) (Salam, 2009). Drumwright (1994) introduced one of the original designations of PSR, "which attempts to take into account the public consequences of organisational buying or bring about positive social change through organisational buying behaviour."

This specific definition of PSR, which summaries Carroll's definition of CSR, is used in the present study: "purchasing activities that meet the ethical and discretionary responsibilities expected by society". PSR may turn out to be an important source of sustainable competitive advantage for companies (Carter \& Jennings, 2004), as a key driver in the development of more sustainable products and supply chain practices.

\subsection{The Impact of Leadership and Followership on CSR Adoption}

Several organisations believe that leadership is a crucial challenge, when it comes to the development of workable CSR strategies, redefining the design of organisational systems and processes, and/or falsifying required culture change (Velsor, 2009). According to Ho et al. (2015), to have a socially responsible corporation, the presence of a socially responsible leadership that is available to promote and implement CSR activities for the benefit of the organisation, as well as its stakeholders, is practically mandatory. Balancing issues regarding environment, society and government with the interests of several stakeholders is vital to improve investor perception and public trust (SCM, 2012). The core of a supply chain leadership (SCL) can be seen in the facility of one corporation to be an influence on the activities of another corporation. Secondly, the behaviour anticipated by the supply chain leader might be seen through its stated policies and the actions of boundaryspanning personnel, behaviour which identify the supply chain leader and distinguish it from follower organizations. Thirdly, the supply chain leader is the corporation that recognises the need for change and generates an idea of a better future for the supply chain (Defee, Stank, \& Esper, 2010).

Gosling et al. (2016) propose a conceptual framework on how focal companies assuming a leadership role initiate and disseminate sustainable practices in their supply chains. They emphasize the importance of the leadership role in the supply chain, involving supply chain partners in order to better implement sustainability initiatives. The flip side of leadership is followership (Tinnish, 2017). According to this author, leadership and followership are reciprocal structures. According to Hollander (1992), the capacity to follow the right path, develop an activity according to a plan, successfully integrate a team and deliver the expected outputs is called followership. Followership can be proactive, directly influencing firm performance, although this characteristic is usually expected in leadership. Tinnish (2017) considers that firms who promote CSR programs contribute to the appearing of an increased number of proactive followers, which can actively contribute to the traditional leadership process. Even though leadership has an important role, most of the work done by a corporation results directedly from the contributions of followers (Kelly, 2004). Effective followers are categorized as people who work honestly according to their own values (Lundin \& Lancaster, 1990), share with leaders the determination to achieve common goals and value their role to offer constructive criticism to their leaders, willingly challenging inappropriate behaviour that strays from mutually held goals established between leaders and followers. By establishing important relationships between follower beliefs, displacement of responsibility and obedience, they have pointed out that we are only now beginning to understand the follower's role in a truly ethical leadership, since followers can challenge their leader to adopt ethical conducts, and therefore CSR.

Consequently, the following hypotheses are proposed:

H1: SCL has a positive impact on CSR.

H2: SCF has a positive impact on CSR. 


\subsection{The Mediating Role of Information Sharing, Shared Values and Purchasing Social Responsibility}

$\mathrm{Li}$ et al. (2014) considered that IS in the supply chain refers to the communication and transmission of information among supply chain parties during processes of transaction and cooperation. Sahin and Robinson (2002) stated that IS is a crucial element for supply chain management and has been recognised as one of the five building blocks of a strong supply chain relationship. It is critical to the efficiency, effectiveness, and competitive advantage of any supply chain system (Li, Ye, \& Sheu, 2014). In teamwork or workplaces, any successful process or activity depends on the relationship between leadership and followership. In their relationship with followers, leaders need to show that they can be trusted. This can be achieved through acting as role models, involving followers in the process of making major decisions, and supporting followers through information sharing and the provision of necessary resources to accomplish teamwork.

Consequently, the following hypothesis is proposed:

H3: SCL has a positive impact on IS.

To respond to modern industry challenges, the role that followers have in business has changed considerably in the last years. Recent transformations in the worldwide economy are producing a favourable environment for the conception of "new models of followership" (Chaleff, 2003). In the past century, a strong leadership was considered as the best choice to assure that the firms' objectives were accomplished. According Chaleff (2003), in "information-age organizations", the business environment has become complex, with several interconnected business partners working together to achieve the same goals. In this challenging context, there is a call for leadership behaviour at different levels of the supply chain to assure that business is efficiently coordinated, enabling IS. Therefore, IS may be the missing link to understand how followership relates to a social responsible purchasing.

Consequently, the following hypothesis is proposed:

H4: SCF has a positive impact on IS.

Radaelli et al. (2014) argue that organizations that consider knowledge as a strategical subject that must be properly managed and shared, both inside and outside organizations limits, have a superior capability to innovate and increase their performance. Wang and Noe (2010) explain that as work processes are becoming more interdependent at all levels, every person, team and organization needs to constantly break existing "knowledge silos", enabling synergies between different skills and knowledge background, continually promoting improvement and organizational innovation.

Consequently, the following hypothesis is proposed:

H5: IS has a positive impact on CSR.

The values of an organization are in the core of organizational culture, which can be defined as the elementary pattern of common assumptions, values, and beliefs considered the correct way of thinking about and acting on problems and opportunities facing the organization (Amah \& Ahiauzu, 2014). In other words, values dictate what is a priority, a preference or a desire for each of us. Values and motives for action are believed to be in the root of leadership and followership. It is important for leaders understanding the best way to use the insight of how their needs and values lead to the creation of goals and strategies that stimulate their staff and shape the culture to create more shareholder's value. Leaders have the important role of translating their mission, goals and strategies into the operative values of their direct reports and employees, so they can create tomorrow's company today, while accommodating their leadership style to lead a culture with people that have different needs and values and optimising value for shareholders and stakeholders. Shared values are a major characteristic of a strong organisational culture that supports a mutual purpose and creates commitment to it. According to Gill (2003), the importance of values-based leadership has been highlighted by the challenge of change. O'Toole (1995) stated that there is a general belief among corporate executives regarding the necessity of creating strong shared values to bring people together in a fragmented world. As a result, SCL and SCF entails identifying and promoting shared values (Allen, 2016).

Consequently, the following hypotheses are proposed:

H6: SCL has a positive impact on SV.

H7: SCF has a positive impact on SV.

Numerous studies, which are included in the theoretical context of CSR and can be found 
within ethical theories, highlight in what way entrepreneurial behaviour and values are in the base of strategies and actions concerned with CSR (Baldo, 2016). The literature regarding ethic in business emphasizes the values dimension of entrepreneurial and managerial activity, introducing concepts like management integrity, authenticity and virtues. These ideas are wide spreading in the corporate context, helping rise the model of good governance, intended to construct a more civil economy (Argandoña, 2003). Broon (2001) considers that the concept of CSR is strongly associated with the fundamental values of a corporation. As such, it is reflected in both the vision statement and the more detailed mission statements of the organization, which assures that at least the aspirations and guiding values that are linked to the CSR concept are preserved. According to Butt et al. (2016), a sustainable leadership creates ethical values, contributing to social responsibility behaviour of the organizations.

Consequently, the following hypothesis is proposed:

H8: SV has a positive impact on CSR.

PSR includes a large variety of matters, like the environment, labour and human rights, health and safety, employee training, fair trade, animal welfare and philanthropy (Bjorklund, 2010). A problem discussed by Maignan et al. was that purchasing professionals were not aware of how they could adopt the rising expectations of social responsibility from their customers. From that moment on, the establishment of the research field by defining the concept, dimensions and drivers that comprise PSR has been the focus. The purchasing managers span the border between the company's internal functions and its external stakeholders, including suppliers and third parties. Thus, purchasing is favourably positioned to affect the companies' involvement in social responsible activities. If a firm adopts social and/or environmental standards, the purchasing function can be used in transferring them to suppliers. In this case, the corporation will generate a chain effect by which fast and significant social and environmental changes can be triggered (Preuss, 2000). Carter and Jennings (2004) found that a people-oriented culture leads to higher levels of responsibility in accomplishing purchasing activities.

Consequently, the following hypotheses are proposed:
H9: SCL has a positive impact on PCR. H10: SCF has a positive impact on PCR.

The implementation of PSR requires it to be internalized in the purchasing company. There must be the definition, communication and monitorization of standards of conduct with the supplier. Furthermore, the corporation must have constant suppliers' selection criteria, aligning its purchasing strategies with the supplier's relationships and share the cost of compliance with the supplier (Lau, 2011). According to Boyd et al. (2007), the implementation of CSR within the supply chain usually requires the supplier's compliance and monitoring. The use of following guidelines that are transparent, ethical and impartial in inter-firm relations can be an effective mean to increase compliance. Mont and Leire (2009) proposed that a few selected associates of the company should have the responsibility when it comes to the development and implementation of PSR in the supply chain, considering leadership a main driver of ethical behaviour related with purchasing.

Consequently, the following hypothesis is proposed:

H11: PCR has a positive impact on CSR.

\subsection{The Moderating Role of Supply Chain Leadership Dependency}

The supply chain relationships have their base on ties of shared dependence in which one part has a certain amount of control over the achievement of its own aims and the ones of other parties (Narasimhan, Nair, \& Griffith, 2009). Cadden et al. (2015) consider that one party has more power when it can accomplish the goals of another supply chain member. To develop positive relationships, a member should take action in a relational way, instead of maximising its own position. Channel members need to depend on one another in accomplishing their common goals, once each one is expert in the activity that lies in their core competencies. These functions comprise information, promotion, negotiation, etc., and all flow forward and/or backward through the channel. Narasimhan et al. (2009) stated that power is extensively described as a central matter when it comes to researching the supply chain management. When the buyer is highly dependent and the dependence of the supplier is low, there is a supplier's power and opportunistic behaviour may be seen. 


\section{Business Administration and Management}

The reverse situation is also real, that is, when the supplier is highly dependent on the buyer but the buyer dependency on the supplier is low, there is buyer power and the buyer will try to use it to affect the supplier's behaviour. Nevertheless, Cadden et al. (2015) say that in the case of both being highly dependent on each other, there is interdependence and this environment is where more cooperative cultures can be formed and developed.

In the present study, we consider the moderator effect of supply chain leadership dependency (SCLD) that corresponds to the supplier's dependency on the supply chain leader company. Accordingly, the follower's dependency may create a special predisposition to adopt and interact with specific behaviour, namely, sharing values, sharing information and reinforcing their social responsible behaviour on the purchasing decisions.

\section{Method}

The research model presents a set of hypotheses. Given that each supplier has a different perception of the variables of the present investigation according to the level of dependency related with the supply chain leaser, SCLD is considered a moderating variable. Consequently, two groups are created to consider the impact of SCLD: a group with low SCLD $(n=198)$ and a group with high SCLD $(n=227)$. The proposed hypotheses are analysed overall and also according to each group, to test the impacts of SCLD on the proposed relationships. The following research model shows the main hypotheses considered in the present investigation (see Fig. 1).

\subsection{Sample and Data Collection}

A questionnaire was developed using the online LimeSurvey tool to test the proposed

\section{Fig. 1: Conceptual model}

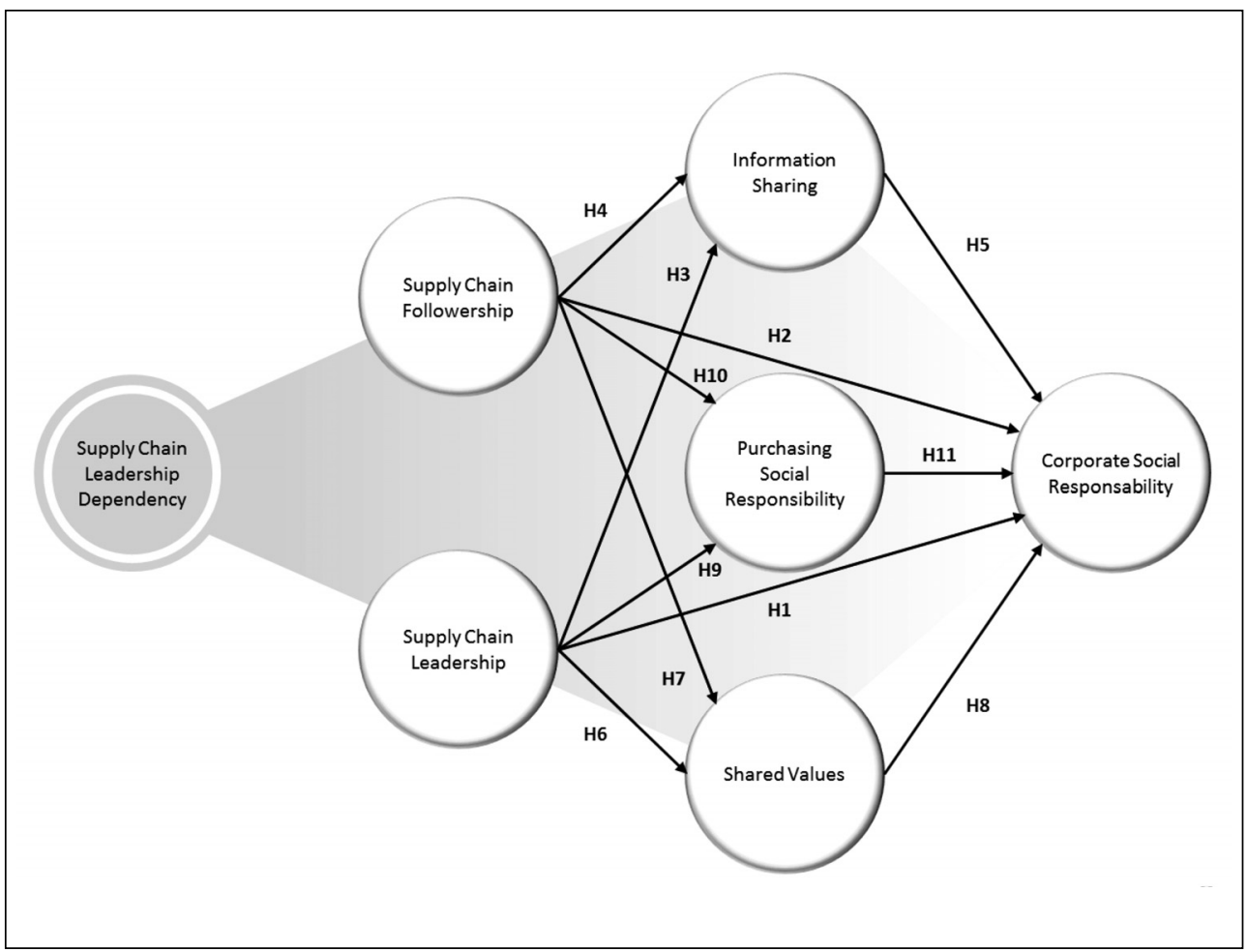


research model and hypotheses. Between June and September 2016, all the 1,466 critical suppliers of EDP Group - considering its overall universe of 5,275 suppliers that execute activities in Portugal - were contacted by e-mail to respond to the questionnaire. EDP is a vertically integrated utility company, and the largest generator, distributor and supplier of electricity in Portugal, the third largest electricity generation company in the Iberian Peninsula and one of the largest gas distributors in the Iberian Peninsula, with relevant presence in the world's energy landscape. EDP was chosen because of its involvement and commitment to CSR as well as because of its power and leadership in the market which gives it the supremacy to exert an effective influence in the supply chain, to disseminate the social practices adoption.

In the last years, EDP has aggressively invested in Sustainable Development and on marketing. EDP recognises the importance of sustainability in its operations and value chain, and integrates the economic, environmental and social opportunities and risks into its business strategy (EDP, 2016a). From the 1,466 EDP which were contacted, only 979 agreed to participate in this survey. Of the 979 questionnaires collected, 425 were validated for use, the other 554 being rejected for incompleteness. The respondents were workers delegated by their companies to represent the contractual relation towards EDP namely CEO/ Managers (18.6\%), Chief Executives (41.3\%), Supervisors (13.0\%), Office Managers (10.1\%), Operators $(1.7 \%)$ and other positions (15.3\%). $66 \%$ have less than 50 workers, $10 \%$ between 50 and $100,24 \%$ more than 100 . The annual income average is $22,758 \mathrm{k} €$, and $24.8 \%$ of this companies are form commerce, $10.7 \%$ are form industry, and $64.5 \%$ are from services.

\subsection{Measures}

The measures were created after reviewing the literature in the field and adapting scales that had already been validated in other research investigations. Such adaption included the translation of vocabulary from English to Portuguese, to be more appropriate and hence more easily understood by respondents. Each scale included a combination of items from existing scales adapted to the present study. Scale items are shown in Tab. 1. A seven-point Likert scale was used and participants were instructed to answer to each item based on the frequency of the actions they observed, ranging from "Not at all" (1) to "Frequently" (7).

\section{Tab. 1: Conceptual model - Part 1}

\begin{tabular}{|c|c|}
\hline CONSTRUCT & ITEM \\
\hline \multirow{2}{*}{$\begin{array}{l}\text { Supply Chain } \\
\text { Leadership } \\
\text { - SCL - } \\
\text { (Defee, Stank, \& } \\
\text { Esper, 2010) }\end{array}$} & My supply chain leader (...) \\
\hline & $\begin{array}{l}\text { (1) Articulates a compelling vision of the supply chain's future; (2) Clarifies the } \\
\text { central purpose underlying actions of all supply chain members; ( } 3 \text { ) Seeks } \\
\text { differing perspectives from my company when solving problems; (4) Induces my } \\
\text { company to look at problems from many different angles; (5) Asks my company } \\
\text { to contribute with ideas for improving supply chain problems; (6) Helps my } \\
\text { company to strengthen the supply chain execution; (7) Encourages my } \\
\text { company to continuously improve its supply chain skills. }\end{array}$ \\
\hline \multirow{2}{*}{$\begin{array}{l}\text { Supply Chain } \\
\text { Followership } \\
\text { - SCF - } \\
\text { (Defee, Stank, \& } \\
\text { Esper, 2010) }\end{array}$} & My company (...) \\
\hline & $\begin{array}{l}\text { (1) Independently thinks of new ideas that contribute to the supply chain goals; } \\
\text { (2) Champions the need for change in the supply chain; (3) Builds a record } \\
\text { of success in tasks important to the supply chain leader; (4) Seeks out and } \\
\text { completes assignments that go above and beyond what's required; (5) Makes } \\
\text { sound decisions that benefit the entire supply chain; (6) Works hard to support } \\
\text { the supply chain leader's goals; (7) Develops a network of relationships with } \\
\text { other supply chain members; (8) Strives to accomplish goals that have been } \\
\text { mutually defined with the supply chain leader; (9) Contributes at a high level } \\
\text { when not in a leadership position; (10) Demonstrates commitment to overall } \\
\text { supply chain success. }\end{array}$ \\
\hline
\end{tabular}




\begin{tabular}{l|}
\multicolumn{1}{c|}{ CONSTRUCT } \\
\hline Information Sharing \\
- IS1 - \\
(Li, Ye, \& Sheu, 2014)
\end{tabular}

(Li, Ye, \& Sheu, 2014)

\section{ITEM}

My supply chain leader shares his (...)

(1) Production planning information with us; (2) Production capacity information with us; (3) Inventory information with us.

We share with our supply chain leader (...)

(1) Our production planning information; (2) Demand forecast information.

The information shared by our supply chain leader and us is (...)

(1) Timely; (2) Accurate; (3) Complete; (4) Adequate; (5) Reliable.

\section{Shared Values \\ - SV - \\ (Panayides, 2007) \\ Purchasing Social Responsibility - PSR -}

(Salam, 2009)

\begin{tabular}{l|}
\hline Corporate Social \\
Responsibility \\
\cline { 2 - 2 } - CSR - \\
(Rettab, Brik, \& \\
Mellahi, 2009) \\
Community
\end{tabular}

\section{Considering my supply chain leader (...)}

(1) We share the same world's view; (2) We share opinions about most things;

(3) We share the same feelings towards things around us; (4) We share the same values.

\section{The purchasing relation of my company with my supply chain leader contributes to (...)}

(1) My responsibility towards the environment; (2) My responsibility towards diversity; (3) My responsibility towards human rights; (4) My responsibility towards safety; (5) My responsibility towards philanthropy.

\section{My company (...)}

(1) Give money to charities in the communities where we operate; (2) Help improve the quality of life in the communities where we operate; (3) Financially support community activities (arts, culture, sports); (4) Financially support education in the communities where we operate.

Environment

(1) Incorporate environmental performance objectives in organisational plans;

(2) Voluntarily exceed government environmental regulations; (3) Financially support environmental initiatives; (4) Measure the organisation's environmental performance.

Employees

(1) Treat all employees fairly and respectfully, regardless of gender or ethnic background; (2) Provide all employees with salaries that properly and fairly reward them for their work; (3) Support all employees who want to pursue further education; (4) Help all employees coordinate their private and professional lives; (5) Incorporate the interests of all employees into business decisions.

\begin{tabular}{l|l}
\hline Investors & $\begin{array}{l}\text { (1) Incorporate the interests of all our investors into business decisions; } \\
\text { (2) Provide all investors with a competitive return on investment; (3) Seek the } \\
\text { input of all our investors regarding strategic decisions; (4) Meet the needs and } \\
\text { requests of all our investors. }\end{array}$ \\
\hline Customers & $\begin{array}{l}\text { (1) Provide all customers with very high-quality service; (2) Provide all } \\
\text { customers with the information needed to make sound purchasing decisions; } \\
\text { (3) Satisfy the complaints of all customers about the company's products or } \\
\text { services; (4) Adapt products or services to enhance the level of customer } \\
\text { satisfaction. }\end{array}$ \\
\hline Suppliers & $\begin{array}{l}\text { (1) Provide all suppliers of products and services with a commitment to } \\
\text { a future relationship; (2) Offer all suppliers of products and services some } \\
\text { price guarantees for the future; (3) Incorporate the interests of all suppliers } \\
\text { of products and services into business decisions; (4) Involve all suppliers in } \\
\text { new product or service development; (5) Inform all suppliers of products and } \\
\text { services about organisational changes affecting purchasing decisions. }\end{array}$ \\
\hline
\end{tabular}


Confirmatory factor analysis was used to evaluate the psychometric properties of the scales and the measurement model, using AMOS 22. The final model shows a good fit $(\mathrm{IFI}=0.951 ; \mathrm{TLI}=0.945 ; \mathrm{CFI}=0.951$; RMSEA $=0.065 ; \quad \mathrm{CMIN} / \mathrm{DF}=2.771$; $\mathrm{GFI}=0.865)$. The two dimensions of IS showed high correlations and were turned into a second order variable. All the scales had values above 0.79 in the composite reliability (CR) and above 0.64 in the average variance extracted (AVE), as recommended by Hair et al. (2006). The means, standard deviations, square correlations, Cronbach's alpha, composite reliability, and average variance extracted are presented in Tab. 2. Discriminant validity is evidenced by the fact that all correlations between the constructs are significantly smaller than 1 and the squared correlations calculated for each pair of constructs is always smaller than the variance extracted for correspondent constructs (Shiu et al., 2011), with the marginal exception of IS, thereby confirming the discriminant validity.

\begin{tabular}{|c|c|c|c|c|c|c|c|c|c|}
\hline \multirow[t]{2}{*}{ Tab. 2: } & \multicolumn{9}{|c|}{$\begin{array}{l}\text { Standard deviation, correlations, Cronbach's alpha, composite reliability } \\
\text { and average variance extracted }\end{array}$} \\
\hline & SD & SCL & SCF & IS & SV & PCR & CSR & CR & AVE \\
\hline SCL & 1.084 & 0.950 & & & & & & 0.938 & 0.751 \\
\hline SCF & 0.943 & 0.265 & 0.935 & & & & & 0.849 & 0.585 \\
\hline IS & 1.329 & 0.676 & 0.308 & 0.946 & & & & 0.786 & 0.678 \\
\hline sv & 1.223 & 0.406 & 0.326 & 0.540 & 0.928 & & & 0.928 & 0.763 \\
\hline PSR & 1.479 & 0.397 & 0.125 & 0.471 & 0.442 & 0.940 & & 0.931 & 0.773 \\
\hline CSR & 0.868 & 0.095 & 0.305 & 0.229 & 0.401 & 0.176 & 0.949 & 0.866 & 0.526 \\
\hline
\end{tabular}

Source: own

Note: The principal diagonal presents Cronbach's alpha; SD = Standard deviation; $C R=$ Composite reliability; $\mathrm{AVE}=$ Average variance extracted

\subsection{Common Method Variance}

To minimize the risk of common method variance, we used some procedural methods proposed by Podsakoff et al. (2003): (a) all respondents were guaranteed anonymity and confidentiality of the information collected, and assured that there were no right or wrong answers; (b) there was randomness in the ordering of multiple items; (c) there was no use of scales with bipolar numerical values and verbal designations for the mid-points of the scales; (d) the questionnaire was divided into several sections with a brief explanation, reducing the risk of common method bias (Brammer \& Millington, 2008). A single factor test was also performed. A principal component analysis (unrotated solution) of all the items revealed 12 factors with values above 1 . They accounted for $78 \%$ of the total variance, the first of which explained only $27 \%$ of the variance, suggesting that there were no problems with the common method variance. A single factor solution was tested (Podsakoff \& Organ, 1986) and the fit of the model was very poor: $\mathrm{IFI}=0.381$; $\mathrm{TLI}=0.358 ; \mathrm{CFI}=0.379 ;$ RMSEA $=0.149$; $\mathrm{CMIN} / \mathrm{DF}=10.460 ; \mathrm{GFI}=0.240$. All the methods used showed that there were no problems with common method variance.

\section{Findings}

To perform a confirmatory factor analysis and structural equation modelling to test the hypotheses, it was used Amos 22. The final model shows a good fit $(\mathrm{IFI}=0.931 ; \mathrm{TLI}=0.927$; $\mathrm{CFI}=0.931 ; \mathrm{RMSEA}=0.057 ; \mathrm{CMIN} / \mathrm{DF}=2.383$; GFI $=0.793$ ). Two groups were created for SCLD based on the level of dependence of the partners towards the leader: the group with dependence above the average and the group with dependence below the average. The first group, with lower SCLD levels was composed by 198 respondents, while the second group, with higher SCLD levels, was composed by 227 respondents. A multi-group analysis was performed to identify the differences between the two groups. The results presented in Tab. 3 
Tab. 3: Standardized regression summary

\begin{tabular}{|c|c|c|c|c|c|c|c|c|c|c|c|c|c|c|c|}
\hline \multirow{2}{*}{\multicolumn{4}{|c|}{ HYPOTHESIS }} & \multicolumn{4}{|c|}{ GLOBAL } & \multicolumn{4}{|c|}{ LOW SCLD } & \multicolumn{4}{|c|}{ HIGH SCLD } \\
\hline & & & & SRW & C.R. & $P$ & CHECK & SRW & C.R. & $P$ & CHECK & SRW & C.R. & $P$ & CHECK \\
\hline H1 & $S C L$ & $\triangleright$ & CSR & -0.475 & -3.973 & $* \star *$ & $\otimes$ & -0.488 & -3.816 & $* * *$ & $\otimes$ & -0.538 & -2.023 & 0.021 & $\otimes$ \\
\hline $\mathrm{H} 2$ & SCF & $D$ & CSR & 0.371 & 4.620 & $* * *$ & $\checkmark$ & 0.399 & 3.522 & $* * *$ & $\checkmark$ & 0.334 & 2.489 & 0.006 & $\checkmark$ \\
\hline H3 & $\mathrm{SCL}$ & $D$ & IS & 0.672 & 11.377 & $* * *$ & $\checkmark$ & 0.559 & 5.933 & $* * *$ & $\checkmark$ & 0.743 & 9.941 & $* * *$ & $\checkmark$ \\
\hline H4 & SCF & $\triangleright$ & IS & 0.277 & 5.001 & $* * *$ & $\checkmark$ & 0.318 & 3.419 & $* * *$ & $\checkmark$ & 0.273 & 4.063 & $* * *$ & $\checkmark$ \\
\hline H5 & IS & $\triangleright$ & CSR & 0.175 & 1.345 & 0.089 & $\otimes$ & 0.036 & 0.277 & 0.391 & $\otimes$ & 0.450 & 1.451 & 0.073 & $\otimes$ \\
\hline $\mathrm{H} 6$ & $\mathrm{SCL}$ & $D$ & SV & 0.423 & 7.732 & $* * *$ & $\checkmark$ & 0.331 & 3.768 & $* * *$ & $\checkmark$ & 0.478 & 7.197 & $* \star *$ & $\checkmark$ \\
\hline H7 & SCF & $\triangleright$ & SV & 0.370 & 6.451 & $* * *$ & $\checkmark$ & 0.375 & 3.991 & $* * *$ & $\checkmark$ & 0.418 & 5.989 & $* * *$ & $\checkmark$ \\
\hline $\mathrm{H} 8$ & SV & $D$ & CSR & 0.526 & 7.455 & $* * *$ & $\checkmark$ & 0.597 & 6.297 & $* * *$ & $\checkmark$ & 0.411 & 3.700 & $* * *$ & $\checkmark$ \\
\hline H9 & $S C L$ & $\triangleright$ & PSR & 0.576 & 9.601 & $* * *$ & $\checkmark$ & 0.475 & 4.983 & $* * *$ & $\checkmark$ & 0.625 & 8.337 & $* * *$ & $\checkmark$ \\
\hline H10 & SCF & $\triangleright$ & PSR & 0.104 & 1.800 & 0.035 & $\checkmark$ & 0.113 & 1.193 & 0.116 & $\otimes$ & 0.142 & 2.041 & 0.020 & $\checkmark$ \\
\hline H11 & PSR & $\triangleright$ & CSR & 0.129 & 2.257 & 0.012 & $\checkmark$ & 0.229 & 3.056 & 0.001 & $\checkmark$ & 0.016 & 0.183 & 0.427 & $\otimes$ \\
\hline
\end{tabular}

show the relationships between the variables of the model and the introduction of SCLD as a moderating variable. Multi-group Moderation Tests were carried out, with the conclusion that the two groups are different.

Additionally, direct, indirect and total effects are presented in Tab. 4 to highlight the proposed mediation effects in the variables considered in the present investigation.

SCL has a negative impact on CSR $(\mathrm{SRW}=-0.475 ; \mathrm{p}=0.000)$, therefore not supporting $\mathrm{H} 1$. This result is valid for both groups considered, namely for the group with higher dependency $(\mathrm{SRW}=-0.538 ; \mathrm{p}=0.021)$ and for the group with lower dependency $(\mathrm{SRW}=-0.488 ; \mathrm{p}=0.000)$. Considering the literature, e.g. Carter and Jennings (2002) and Dubey et al. (2015), it is expected that transformational leadership, based on ethical principles and values, will contribute to the adoption of socially responsible behaviour by the supply chain partners. Literature indicates that followers tend to trail leaders' behaviour, especially when they recognize that those behaviour can contribute to value creation for themselves. However, the results obtained show an antagonistic effect to the existing literature. The leadership practiced by the supply chain leader seems to have a negative effect on the adoption of socially responsible behaviour by the follower companies. Even if sustainable behaviour may be adopted by followers based on contractual relations with the supply chain leader (since they intend to guarantee the

\section{Tab. 4: Direct, indirect and total effects}

\begin{tabular}{l|l|c|c|c|c}
\multicolumn{2}{c|}{} & PSR & SV & IS & CSR \\
\hline \multirow{3}{*}{ SCL } & Total & 0.576 & 0.423 & 0.672 & -0.060 \\
\cline { 2 - 6 } & Direct & 0.576 & 0.423 & 0.672 & -0.475 \\
\cline { 2 - 6 } & Indirect & 0.000 & 0.000 & 0.000 & 0.415 \\
\hline \multirow{3}{*}{ SCF } & Total & 0.104 & 0.370 & 0.277 & 0.627 \\
\cline { 2 - 6 } & Direct & 0.104 & 0.370 & 0.277 & 0.371 \\
\cline { 2 - 6 } & Indirect & 0.000 & 0.000 & 0.000 & 0.257 \\
\hline
\end{tabular}


sustainability of the contractual relationship, fulfilling the established PSR requirements), when followers develop activities in other contexts those social responsible behaviour may not be maintained.

Perhaps, the action of the leader may be too strong, exercising a high pressure that may cause low motivation or rejection, therefore leading to a low CSR involvement. The observed effect may be related with resistance to change of supply chain partners, resulting from the lack of perception of the value of the socially responsible practices promoted by the supply chain leader or the intrinsic inability to change. An excessive pressure of the leader to comply certain practices, without proper explanation regarding their usefulness, through a rigid and coercive approach, can discourage followers from internalizing leader's culture, since they do not understand it and do not recognize its value. Another factor that may explain this phenomenon is the inertia of society and the business in general, that limits responsible behaviour adopted by individuals and organizations.

Concomitantly, considering Tab. 4, the impacts from leadership on CSR may be transferred in an indirect and positive way through SV, PSR and IS. Perhaps, when a supply chain leader (i) shares information with followers, in a systematic and transparent way, (ii) establishes a framework of shared values, with a clear purpose, able to contribute to a collaborative approach, furthering the greater mission of supply chain relationship and (iii) promotes contractual relationships where socially responsible behaviour are encouraged, a favourable environment can be established and supply chain partners can truly become socially responsible enterprises.

SCF has a positive impact on CSR (SRW $=0.371 ; p=0.000$ ), therefore supporting $\mathrm{H} 2$. Considering the literature, e.g. Carsten and Uhl-Bien (2013) and Defee et al. (2010), followership is expected to influence the adoption of social responsible behaviour, namely it is expected that the follower organization internalizes the practices of leader's organizations if they realize that they can contribute to the sustainability of their own business. Suppliers committed to collaborate with leaders in a synergistic way, aware of the importance of teamwork in the leader-follower relationship, will be more predisposed to follow the leader's behaviour and adopting it in their daily lives, since they recognize the value of this conduct for their own organizations.

This result is valid for both groups considered, namely for the group with higher dependency (SRW $=0.334 ; p=0.006)$ and for the group with lower dependency $(\mathrm{SRW}=0.399 ; \mathrm{p}=0.000)$. Followership, contrary to the effects of leadership, may be the acknowledgment that the supply chain has a leader and that the company is following the standards of the leader. The acceptance of a followership position may stimulate a positive attitude towards CSR that is similar for both groups.

SCL has a positive impact on IS $(S R W=0.672 ; p=0.000)$, therefore supporting $\mathrm{H} 3$. According to the literature, e.g. Dubey et al. (2015) and Jennings et al. (2004), leadership is expected to have a positive impact on the availability to share information and to maintain an intense and profitable IS.

This result is valid for both groups considered, namely for the group with higher dependency (SRW $=0.743 ; p=0.000)$ and for the group with lower dependency $(S R W=0.559$; $p=0.000$ ). Leadership appears to have positive influence on IS, stimulating an intense flow of information. This impact is stronger among companies with higher dependency that seam more available to follow the leader. Kumar et al. (2013) consider that leaders who have the power to incite and influence information sharing activities have a natural advantage in their ability to play a central role in the process of knowledge creation and thus build competitive power for organizations. Yet, dependency means that one part of the relationship exerts some kind of power over the other part, which may lead to the adoption of certain behaviour. In this case, the supply chain leader may encourage its suppliers to adopt a social responsible purchasing behaviour, and this effect is more intense in the relationship with more dependent companies.

SCF has a positive impact on IS (SRW $=0.277 ; p=0.000$ ), therefore supporting H4. Followership appears to have an impact on IS. The recognition of a followership position may create the feeling that an intense flow of information may be good for the relationship. IS may be the missing link to understand how followership relates to social responsible purchasing behaviour. King et al. (2009) consider that leadership and followership have 
grown to enable IS and coordinated group action in a wide variety of contexts, arguing that leadership probably evolved initially to solve problems related to IS and social coordination.

Considering SCLD, the results obtained are valid for both groups under review. However, this relationship is more intense for the low dependency group (SRW $=0.318 ; p=0.000)$, for whom cooperation may be better than imposition, than for the high dependency group $(\mathrm{SRW}=0.273 ; \mathrm{p}=0.000)$. Less dependency from supply chain leader may increase the follower's confidence to adopt a more effective information sharing. In certain circumstances, sharing relevant information can improve the supply chain follower's perception concerning the vulnerability against the power of supply chain leaders, especially when the SCLD is high. This situation can negatively affect IS, since the follower eventually considers that less IS can give him some protection and competitive advantages to manage a potentially risky relation with a powerful supply chain leader.

Finally, the relation between IS and CSR $(\mathrm{SRW}=0.175 ; p=0.089)$ is not significant, therefore not supporting H5. According to the literature, e.g. Radaelli et al. (2014) and Khan et al. (2016), corporations that encourage IS inside and outside the organizational limits are more probable to develop innovations and improve their performance, contributing to social responsible behaviour. IS allows the alignment and integration of certain processes, and the homogenization of organizational culture, creating a transparent decision-making platform that improves an open dialogue and encourages the reporting of health and safety issues, rewarded by those who assume leadership responsibilities.

This result is not significant for both groups considered, namely for the group with higher dependency (SRW $=0.450 ; p=0.073$ ) and for the group with lower dependency $(S R W=0.036$; $p=0.277$ ). Subsequent investigations may explore this relationship more precisely. Yet, literature provides significant evidence regarding how IS represents a key factor, in order to promote social responsible behaviour on the organizations, since it can contribute to knowledge dissemination among supply chain partners that can be used to justify behavioural changes, in favour of more sustainable options.

SCL has a positive impact on SV $(S R W=0.423 ; p=0.000)$, therefore supporting
H6. According to the literature, e.g. Amah and Ahiauzu (2014) and Gill (2003), the challenge of change has been stimulating the highlight of values-based leadership that contributes to creating strong shared values which unite people and organizations in a fragmented world, enabling different supply chain partners to work well together to achieve common goals.

This result is valid for both groups considered, however this relationship is more intense for the high dependency group $(\mathrm{SRW}=0.478 ; \mathrm{p}=0.000)$ than for the low dependency group (SRW $=0.331 ; p=0.000)$. High dependency from the supply chain leader may increase the influence of SCL impact on SV, because the remaining less influential supply chain partners are more interested in internalizing the dominant organization culture, guaranteeing the right alignment with the leader responsible for the sustainability of their own business. Avoiding sharing the same values with the supply chain leader could result in a dangerous situation affecting vulnerable companies, dependant from the relationship with the leader, who can be excluded from commercial relations with the leader, due to low-level alignment concerning SV.

Additionally, SCF shows a positive impact on SV (SRW $=0.370 ; p=0.000$ ), therefore supporting $\mathrm{H} 7$. According to the literature, e.g. Yung and Tsai (2013), followership contributes to identify and promote shared values. Considering effective followership points of view, the role of followers should be considered as positive, since it reflects that followers actively engage in the work and provide relevant feedback for leaders to establish SV that enlighten the path of future supply chain decisions.

This result is valid for both groups considered. However, this relationship is more intense for the high dependency group $(S R W=0.418 ; p=0.000)$ than for the low dependency group (SRW $=0.375 ; p=0.000)$. High dependency from supply chain leaders may contribute to this relation, mainly because of the interest of highly dependent followers in keeping a virtuous relation with the leader, with the objective of increasing the commercial relationship.

Finally, SV has a positive impact on CSR (SRW $=0.526 ; p=0.000)$, therefore supporting H8. According to the literature, e.g. Butt et al. (2016), SV can be a powerful agent of positive 
social change, contributing to organizational social responsibility behaviour. A SCL conducted in a sustainable way can enhance ethical values, contributing to organizational social responsibility behaviour, namely with supply chain partners that share the same values of the supply chain leader.

This result is valid for both groups considered. However, the relationship is more intense for the low dependency group $(S R W=0.597 ; p=0.000)$ than for the higher dependency group $(S R W=0.411 ; p=0.000)$. Possibly, under certain circumstances, when the level of dependence is lower, suppliers feel more able to genuinely freely embrace the values shared with the leader, recognizing their importance to build a more sustainable business. When the level of dependence is higher, companies adopt socially responsible values and practices without a truly understanding of their importance, so the relationship will not be so intense, since there is not a true motivation and understanding regarding values alignment and the consequent CSR adoption in activities carried out by supplier's organizations.

SCL has a positive impact on PSR (SRW $=0.576 ; p=0.000$ ), therefore supporting H9. Sustainable supply chain management requires leaders that act as ethical compasses in order to foster socially responsible behaviour in business relationships. Considering Wiengarten et al. (2017), a transformational and inspiring leadership, regarding the environmental, social and economic dimensions of business, in a holistic perspective, covering the medium and long-term horizon, is a key factor for higher PSR levels in contractual relations with suppliers. Thus, it is expected that sustainable leaders, capable of fostering collaboration and the focus on common good, produce socially responsible behaviour on the supply chain partners, who recognize the goodwill of the proposals and ethical standards.

This result is valid for both groups considered. However, the relationship is more intense for the higher dependency group $(\mathrm{SRW}=0.625 ; p=0.000)$ than for the lower dependency group (SRW $=0.475 ; p=0.000)$. Perhaps, companies that are more dependent, are more interested to adopt the defined requirements established by the leader, since they understand that it is strategical to please all the standards and act in a fully collaborative way to assure the sustainability of the contractual relation. Companies with less dependency are not so worried to guarantee this alignment with the leader, since they have other sources of revenues that contribute to maintain their own business. Consequently, suppliers with lower dependency are more unpredictable, and maybe less aligned with supply chain leaders, since they are not so dependent on the leader judgement to survive.

Moreover, SCF has a positive impact on PSR (SRW $=0.104 ; p=0.035$ ), therefore supporting $\mathrm{H} 10$. According to Kim and Schachter (2015), followership is the missing link between leadership and performance, namely the performance related with social responsible behaviour adoption at the purchasing function. The supplier's predisposition to act in a collaborative way is essential to PSR, since it provides synergies for a better alignment with the leader, contributing to value creation for all stakeholders, something that is strategic to business sustainability.

This result is valid only for the higher dependency group (SRW $=0.142 ; p=0.020)$. The results obtained for the lower dependency group were not considered to be statistically significant $(S R W=0.113 ; p=0.116)$. However, it is clear, that followers involved in the leadership process, capable of contributing to a sustainable supply chain in a diligent and committed way, are decisive for the maintenance of socially responsible business relationships, advantageous for all the involved.

Finally, PSR shows a positive impact on CSR (SRW $=0.129 ; p=0.012)$, therefore supporting H11. According to Gold (2017), sustainable supply chain management practices can contribute to firm's performance, and consequently to CSR. When supply chain followers and supply chain leaders develop activities grounded on social responsible principles and behaviour, it is expected that, with the continuity of leader/ follower relationship, followers internalize the practices of the leaders, assuming them as their own, with little differentiation. If the purchasing activities continuously improve social responsible behaviour, in a constructive and synergetic way, it is expected that suppliers change their own behaviour, setting a new paradigm to develop business. CSR becomes part of organization strategy, as consequence of the development of a truly social responsible awareness through meaningful PSR relations with supply chain leaders. 
This result is valid only for the lower dependency group (SRW $=0.229 ; p=0.001$ ). The results obtained for the higher dependency group were not considered to be statistically significant $(S R W=0.016 ; p=0.427)$. Regardless SCLD intensity, the continuity of socially responsible practices in commercial relations may lead to changes in the way companies do business, where more sustainable business approaches will prevail, in detriment of options merely focused in short-term financial results, for a restricted group of stakeholders.

\section{Contributions, Management Implications and Recommendations}

\subsection{Contributions}

According to Cadden, Marshall and Humphrey (2015), literature lacks explanation about the influence of a leadership position to improve social responsibility behaviour across the supply chain as well as about the behaviour of followers considering the supply chain leaders influence. At the same time, the role that dependency may exert on these behaviour are yet to be tested. This investigation contributes to investigation and practice showing: the influence of leadership and followership on the CSR adoption across supply chain; identifying the role of IS, PCR and SV mediating this relationship; establishes the chain of effects between leadership and followership and the CSR adoption; and shows how dependency may affect these relationships. This new approach of supply chain management identifies how a social responsible company may lead their suppliers to adopt and develop a true and committed socially responsible behaviour. Furthermore, this study integrates these ideas and relations in one empirical study with relevant data, offering a model that illustrates a chain of important effects, between the supply chain leadership and social responsible behaviour.

\subsection{Implications for Management}

Most of the literature on CSR focus on individual companies' behaviour and their internal impact on performance and other organizational outcomes (Rajeev et al., 2017). This investigation, for the contrary, focuses on how a company may contribute to the adoption of social practices across the supply chain, due to their supremacy and leadership. The research has concrete implications for experts by drawing their consideration to the encouraging links between SCL and SCF, SV, IS, PSR and CSR. Thus, companies can change their behaviour by emphasizing the importance of a truly committed and diligent leadership and followership, concerned with the creation of value in a holistic and long-term way, specifically through social responsible behaviour, not only in the purchasing activities, but also in the entire organizational activities. Leaders who adopt rigid behaviour, demanding followers' obedience, without a proper explanation, can conduct to a negative engagement of supply chain partners concerning CSR, since suppliers do not feel available to genuinely integrate social responsible behaviour into all organizational domains. Suppliers may feel forced to adopt social responsible behaviour at purchasing function, not truly understanding the advantage of adopting those behaviour. Consequently, in other circumstances, when suppliers perform actions without supply chain leader influence, they may feel impelled to do not adopt the behaviour usually demanded by the leader, because they do not recognize their value, and may even exhibits an antagonistic responsiveness of not adopting the supply chain leader requirements due to some kind of resentment and aversion, of previously having been forced to adopt behaviour in the purchasing function, without a proper explanation and a mutual consent, considering all suppliers personnel, including managers and employees. However, when leaders promote socially responsible behaviour in purchasing relations established with suppliers, and at the same time, share critical information regarding business activities, keeping a shared values framework, where leaders and followers have a common understanding about what is important for both organizations, a truly engagement of supply chain partners with CSR can be achieved, in a lasting and meaningful way. When leaders share information and values in an authentic and inspirational way, followers may feel more motivated to adopt behaviour promoted by the leader in their daily practices, and not just on the purchasing function. In this way, suppliers are more likely to understand the value underlying the intentions of the leader. IS allows to understand the objectives that leader proposes for the 
business, as well as the approach to achieve them. SV allows to confirm that leaders and followers are aligned in the same purpose, searching for advantages that can benefit all the involved partners. If supply chain leaders can inspire and stimulate followers about the goodness of social responsible behaviour, PSR allows suppliers to learn about these behaviour in purchasing context, and later, implement CSR in all activities developed by supplier's companies in a lasting and meaningful way. Present results can help firms realize the importance of SSCM and how leadership and followership can impact the social responsibility of the entire supply chain. Supply chain leaders and followers should develop an understanding of the entire supply chain and then communicate and collaborate with each other to ensure business sustainability. Therefore, with this new approach, it is possible to understand how a socially responsible company may lead their suppliers to adopt and develop true and committed social responsible behaviour, meeting stakeholders' expectations and creating value to business and society in general.

\subsection{Limitations and Recommendations for Future Research}

Regardless of the contributions stated above, it is important to recognise limitations in our study, which can offer an opportunity for future research. Firstly, we specifically focused on a Portuguese energy supplier. Even though this work's environment may be notably effective for studying the SCL/PCR link, future research could be extended to other business environments, such as industries, communications, healthcare, retailing and education. Secondly, the cross-sectional nature of this study keeps us from stating final causal inferences about the relationships between variables. Further longitudinal studies may address this question. Studies following-up the present investigation could also contribute to the improvement of our model, by suggesting other variables that more widely explain the mediating mechanisms that translate SCL and SCF into CSR, and the reasons why supply chain leadership and followership are conducive to social responsible behaviour. Ownership and control are critical variables to be investigated in the adoption of CSR practices.

\section{References}

Allen, M. (2016). Facilitating Group Collaboration and Enhancing Supply Chain Conversations. In (Eds.), Strategic Communication for Sustainable Organizations (pp. 231-272). Cham: Springer. https://doi. org/10.1007/978-3-319-18005-2_7

Amah, E., \& Ahiauzu, A. (2014). Shared values and organizational effectiveness: a study of the Nigerian banking industry. Journal of Management Development, 33(7), 694-708. https://doi.org/10.1108/JMD-09-2010-0065

Argandoña, A. (2003). Fostering values in organizations. Journal of Business Ethics, 45(1-2), 15-28. https://doi.org/10.1023/A:1024164210743

Björklund, M. (2010). Benchmarking tool for improved corporate social responsibility in purchasing. Benchmarking: An International Journal, 17(3), 340-362. https://doi. org/10.1108/14635771011049335

Brammer, S., \& Millington, A. (2008). Does it pay to be different? An analysis of the relationship between corporate social and financial performance. Strategic Management Journal, 29(12), 1325-1343. https://doi. org/10.1002/smj.714

Brønn, P. S. (2001). Corporate mission as a driver of Corporate Social Responsibility. Retrieved from http://home.bi.no/fgl96053/ stockholm.pdf

Butt, A. A, Butt, A. N., \& Ayaz, M. (2016). Impact of Ethical Leadership on Organizational Performance and Mediating Role of Corporate Social Responsibility: Evidence from Banking Sector of Pakistan. International Journal of Management Sciences and Business Research, 5(6), 25-37.

Cadden, T., Marshall, D., Humphrey, P., \& Yang, Y. (2015). Old habits die hard: exploring the effect of supply chain dependency and culture on performance outcomes and relationship satisfaction. Production Planning \& Control, 26(1), 53-77. https://doi.org/10.1080/0 9537287.2013 .848478

Carroll, A. (1979). A Three-Dimensional Conceptual Model of Corporate Performance. Academy of Management Review, 4(4), 497-505. https://doi.org/10.2307/257850

Carsten, M., \& Uhl-Bien, M. (2013). Ethical Followership: An Examination of Followership Beliefs and Crimes of Obedience. Journal of Leadership \&OrganizationalStudies, 20(1),49-61. https://doi.org/10.1177/1548051812465890 
Carter, C. R., \& Jennings, M. M. (2002). Logistics social responsibility: an integrative framework. Journal of Business Logistics, 23(1), 145-180. https://doi. org/10.1002/j.2158-1592.2002.tb00020.x

Carter, C. R., \& Jennings, M. M. (2004). The role of purchasing in the socially responsible management of the supply chain: A structural equation analysis. Journal of Business Logistics, 25(1), 145-186. https://doi. org/10.1002/j.2158-1592.2004.tb00173.x

Chaleff, I. (2003). The Courageous Follower. San Francisco, CA: Berrett-Koehler.

Defee, C. C., Stank, T. P., \& Esper, T. (2010). Performance implications of transformational supply chain leadership and followership. International Journal of Physical Distribution \& Logistics Management, 40(10), 763-791. https://doi.org/10.1108/09600031011093205

Del Baldo, M. (2016). Authentic CSR and Leadership: Towards a Virtues-Based Model of Stakeholder Dialogue and Engagement. The Loccioni Group Experience. In Idowu S., Vertigans S. (Eds.), Stages of Corporate Social Responsibility. CSR, Sustainability, Ethics \& Governance (pp. 179-203). Cham: Springer. https://doi.org/10.1007/978-3-319-43536-7_9

Drumwright, M. E. (1994). Socially responsible organizational buying: environmental concern as a non-economic buying criterion. Journal of Marketing, 58(3), 1-19. https://doi.org/10.2307/1252307

Dubey, R., Gunasekaran, A., \& Ali, S. S. (2015). Exploring the relationship between leadership, operational practices, institutional pressures and environmental performance: A framework for green supply chain. The International Journal of Production Economics, 160, 120-132. https://doi. org/10.1016/j.ijpe.2014.10.001

EDP. (2016a). Sustainability Management Approach 2015. Retrieved from https:// www.edp.com/sites/default/files/portal.com/ documents/sustainability_management_ approach_2015.pdf

Friedman, M. (1962). Capitalism and freedom. Chicago, IL: University of Chicago Press.

Gill, R. (2003). Change management or change leadership? Journal of Change Management, 3(4), 307-318. https://doi. org/10.1080/714023845

Gold, S., \& Schleper, M. C. (2017). A pathway towards true sustainability:
A recognition foundation of sustainable supply chain management. European Management Journal, 35(4), 425-429. https://doi. org/10.1016/j.emj.2017.06.008

Gosling, J., Jia, F., Gong, Y., \& Brown, S. (2016). The role of supply chain leadership in the learning of sustainable practice: toward an integrated framework. Journal of Cleaner Production, 137, 1458-1469. https://doi. org/10.1016/j.jclepro.2014.10.029

Hair, J. F., Black, W. C., Babin, B. J., \& Anderson, R. E. (2006). Multivariate Data Analysis. London: Pearson Education.

Ho, J. A., Ang, Y. H., \& Tee, K. K. (2015). Institutional Corporate Social Responsibility (CSR) Practices: The Influence of Leadership Styles and Their Perceived Ethics and Social Responsibility Role. Pertanika Journal of Social Science \& Humanities, 23, 17-32.

Hollander, E. P. (1992). Leadership, Followership, Self, and Others. Leadership Quarterly, 3(1), 43-54. https://doi. org/10.1016/1048-9843(92)90005-Z

Keating, B., Quazi, A., Kriz, A., \& Coltman, T. (2008). In pursuit of a sustainable supply chain: insights from Westpac Banking Corporation. Supply Chain Management: An International Journal, 13(3), 175-179. https://doi.org/10.1108/13598540810871217

Kelley, R. E. (2004). Followership. In G. R. Goethals, G. J. Sorenson, \& J. M. Burns (Eds.), The Encyclopedia of Leadership (pp. 504-513). Thousand Oaks, CA: Sage.

Khan, M., Hussain, M., \& Saber, H. M. (2016). Information sharing in a sustainable supply chain. International Journal of Production Economics, 181(Part A), 208-214. https://doi. org/10.1016/j.ijpe.2016.04.010

Kim, C., \& Schachter, H. L. (2015). Exploring Followership in a Public Setting: Is It a Missing Link Between Participative Leadership and Organizational Performance? American Review of Public Administration, 45(4), 436-457. https://doi.org/10.1177/0275074013508219

King, A. J., Johnson, D. D. P., \& Van Vugt, M. (2009). The origins and evolution of leadership. Current Biology, 19(19), 911-916. https://doi. org/10.1016/j.cub.2009.07.027

Kumar, K. K., Jain, K. K., \& Tiwary, R. R. (2013). Leadership activities and their impact on creating knowledge in Organizations. International Journal of Leadership Studies, 8(1), 15-27. https://doi.org/10.2139/ ssrn.2045461 
Lantos, G. P. (2001). The boundaries of strategic corporate social responsibility. Journal of Customer Marketing, 18(7), 595-630. https://doi.org/10.1108/07363760110410281

Lau, A. K. W. (2011). The implementation of social responsibility in purchasing in Hong Kong Pearl River Delta: A case study. Strategic Outsourcing: An International Journal, 4(1), 13-46. https://doi.org/10.1108/ 17538291111108417

Li, Y., Ye, F., \& Sheu, C. (2014). Social capital, information sharing and performance: Evidence from China. International Journal of Operations \& Production Management, 34(11), 1440-1462. https://doi.org/10.1108/ IJOPM-03-2013-0132

Lundin, S. C., Lancaster, L. C., \& Gardner, J. W. (1990). The importance of followership. The Futurist, 24(3), 18-22.

Mont, O., \& Leire, C. (2009). Exploring socially responsible purchasing in Swedish organizations. Social Responsibility Journal, 5(3), 388-407. https://doi.org/10.1108/17471110910977302

Narasimhan, R., Nair, A., Griffith, D. A., Arlbjørn, J. S., \& Bendoly, E. (2009). Lock-in Situations in Supply Chains: Social Exchange Theoretic Study of Sourcing Arrangements in Power-based Buyer-supplierRelationship. Journal of Operations Management, 27(5), 374-389. https://doi.org/10.1016/j.jom.2008.10.004

O'Toole, J. (1995). Leading Change: Overcoming the Ideology of Comfort and the Tyranny of Custom. San Francisco, CA: Jossey-Bass.

Panayides, P. M. (2007). Effects of Organizational Learning in Third-Party Logistics. Journal of Business Logistics, 28(2), 113-158. https://doi.org/10.1002/j.2158-1592.2007. tb00061.x

Podsakoff, P. M., \& Organ, D. W. (1986). Self-reports in organizational research: Problems and prospects. Journal of Management, 12(4), 531-544. https://doi. org/10.1177/014920638601200408

Podsakoff, P. M., MacKenzie, S. B., Lee, J.Y., \& Podsakoff, N. P. (2003). Common method biases in behavioural research: a critical review of the literature and recommended remedies. Journal of Applied Psychology, 88(5), 879-903. http://dx.doi.org/10.1037/0021-9010.88.5.879

Preuss, L. (2001). In dirty chains? Purchasing and greener manufacturing. Journal of Business Ethics, 34(3-4), 345-359. https://doi.org/10.1023/A:1012549318786
Radaelli, G., Lettieri, E., Mura, M., \& Spiller, N. (2014). Knowledge Sharing and Innovative Work Behaviour in Healthcare: A Micro-Level Investigation of Direct and Indirect Effects. Creativity and Innovation Management, 23(4), 400-414. https://doi.org/10.1111/caim.12084

Rajeev, A., Rupesh, K. P., Padhi, S. S., \& Govindan, K. (2017). Evolution of sustainability in supply chain management: A literature review. Journal of Cleaner Production, 162, 299-314. http://dx.doi.org/10.1016/j.jclepro.2017.05.026

Rettab, B., Brik, A. B., \& Mellahi, K. (2009). A Study of Management Perceptions of the Impact of Corporate Social Responsability on Organizational Performance in Emerging Economies: The Case of Dubai. Journal of Business Ethics, 89(3), 371-390. https://doi. org/10.1007/s10551-008-0005-9

Sahin, F., \& Robinson, E. P. (2002). Flow Coordination and Information Sharing in Supply Chains: Review, Implications, and Directions for Future Research. Decisions Sciences, 33(4), 505-536. https://doi. org/10.1111/j.1540-5915.2002.tb01654.x

Salam, M. A. (2009). Corporate social responsibility in purchasing and supply chain. Journal of Business Ethics, 85(2), 355370. Retrieved from https://www.jstor.org/ stable/40294846

SCM. (2012). Malaysian Code on Corporate Governance. Securities Commission Malaysia.

Shiu, E., Pervan, S. J., Bove, L. L., \& Beatty, S. E. (2011). Reflections on discriminant validity: Reexamining the Bove et al. (2009) findings. Journal of Business Research, 64(5), 497-500. https://doi.org/10.1016/j.jbusres.2010.04.004

Szegedi, K., \& Kerekes, K. (2012). Challenges of Responsible Supply Chain Management. Club of Economics in Miskolc, 8(2), 68-75.

Tang, C. S., \& Zhou, S. (2012). Research advances in environmentally and socially sustainable operations. European Journal of Operational Research, 223(3), 585-594. https://doi.org/10.1016/j.ejor.2012.07.030

Tinnish, S. (2014). Engaging Employees Around Corporate Social Responsibility Programs. Hotel Business Review. Retrieved from https://www.hotelexecutive.com/ business_review/4076/engaging-employeesaround-corporate-social-responsibility-csrprograms

Van Velsor, E. (2009). Introduction: Leadership and corporate social responsibility. 


\section{Business Administration and Management}

Corporate Governance, 9(1), 3-6. https://doi. org/10.1108/14720700910936010

Walker, H., Di Sisto, L., \& McBain, D. (2008). Drivers and barriers to environmental supply chain management practices: Lessons from the public and private sectors. Journal of Purchasing and Supply Management, 14(1), 69-85. https://doi.org/10.1016/j.pursup.2008.01.007

Wang, S., \& Noe, R. A. (2010). Knowledge Sharing: A Review and Directions for Future Research. Human Resource Management Review, 20(2), 115-131. https://doi. org/10.1016/j.hrmr.2009.10.001
Wiengarten, F., Lo, C. K. Y., \& Lam, J. Y. K. (2017). How does Sustainability Leadership Affect Firm Performance? The Choices Associated with Appointing a Chief Officer of Corporate Social Responsibility. Journal of Business Ethics, 140(3), 477-493. https://doi. org/10.1007/s10551-015-2666-5

Yung, C. T., \& Tsai, K. C. (2013). Followership: An Important Partner of Leadership. Business and Management Horizons, 1(2), 47-55. http://dx.doi.org/10.5296/bmh.v1i2.4233 